BRAZILLAN JOURNAL

www.bjournal.com.br
ISSN 0100-879X

Volume 43 (3) 182-267 March 2011

BIOMEDICAL SCIENCES

AND

CLINICAL INVESTIGATION

Braz J Med Biol Res, March 2011, Volume 44(3) 229-235

doi: 10.1590/S0100-879X2011007500012

The effects of stretching on the flexibility, muscle performance and functionality of institutionalized older women

D. Gallon, A.L.F. Rodacki, S.G. Hernandez, B. Drabovski, T. Outi, L.R. Bittencourt and A.R.S. Gomes

The Brazilian Journal of Medical and Biological Research is partially financed by

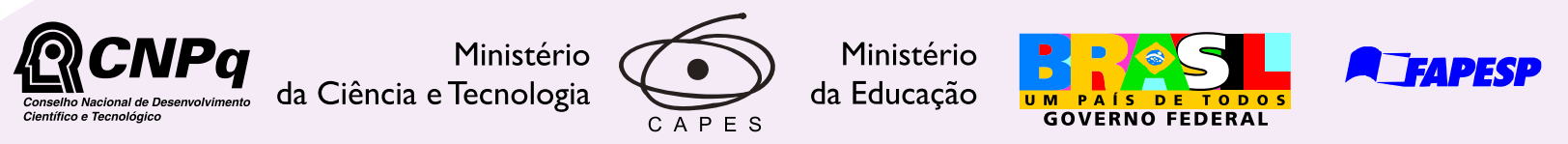

Institutional Sponsors
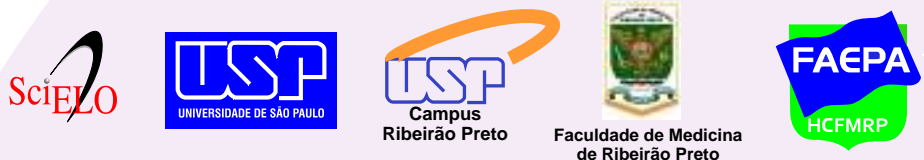

de Ribeirão Predic
Ministério

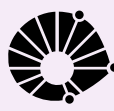

UNICAMP $\oplus$ SHIMADZU

GE Healthcare
Hotsite of proteomics metabolomics developped by:

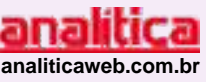

Thermo SCIENTIFIC 


\title{
The effects of stretching on the flexibility, muscle performance and functionality of institutionalized older women
}

\author{
D. Gallon ${ }^{1,2,5}$, A.L.F. Rodacki², S.G. Hernandez ${ }^{3}$, B. Drabovski², T. Outi ${ }^{4}$, \\ L.R. Bittencourt ${ }^{3}$ and A.R.S. Gomes ${ }^{1,2}$ \\ ${ }^{1}$ Departamento de Fisioterapia, Universidade Federal do Paraná, Matinhos, PR, Brasil \\ 2Departamento de Educação Física e Programa de Mestrado e Doutorado em Educação Fisica, \\ Universidade Federal do Paraná, Curitiba, PR, Brasil \\ ${ }^{3}$ Clínica do Atleta, Curitiba, PR, Brasil \\ ${ }^{4}$ Asilo São Vicente de Paulo, Curitiba, PR, Brasil \\ ${ }^{5}$ Departamento de Educação Física, Centro Universitário Franciscano, Curitiba, PR, Brasil
}

\begin{abstract}
Stretching has been widely used to increase the range of motion. We assessed the effects of a stretching program on muscletendon length, flexibility, torque, and activities of daily living of institutionalized older women. Inclusion/exclusion criteria were according to Mini-Mental State Examination (MMSE) (>13), Barthel Index (>13) and Lysholm Scoring Scale (>84). Seventeen $67 \pm 9$-year-old elderly women from a nursing home were divided into 2 groups at random: the control group $(C G, N=9)$ participated in enjoyable cultural activities; the stretching group ( $\mathrm{SG}, \mathrm{N}=8$ ) performed active stretching of hamstrings, 4 bouts of $1 \mathrm{~min}$ each. Both groups were supervised three times per week over a period of 8 weeks. Peak torque was assessed by an isokinetic method. Both groups were evaluated by a photogrammetric method to assess muscle-tendon length of uni- and biarticular hip flexors and hamstring flexibility. All measurements were analyzed before and after 8 weeks by two-way ANOVA with the level of significance set at $5 \%$. Hamstring flexibility increased by $30 \%$ in the SG group compared to pre-training (76.5 $\pm 13.0^{\circ}$ vs $\left.59.5 \pm 9.0^{\circ}, \mathrm{P}=0.0002\right)$ and by $9.2 \%$ compared to the $C G$ group $\left(76.5 \pm 13.0^{\circ}\right.$ vs $\left.64.0 \pm 12.0^{\circ}, P=0.0018\right)$. Muscletendon lengths of hip biarticular flexor muscles $\left(124 \pm 6.8^{\circ}\right.$ vs $\left.118.3 \pm 7.6^{\circ}, 5.0 \pm 7.0 \%, P=0.031\right)$ and eccentric knee extensor peak torque were decreased in the CG group compared to pre-test values $(-49.4 \pm 16.8 v s-60.5 \pm 18.9 \mathrm{Nm},-15.7 \pm 20 \%, P=$ 0.048 ). The stretching program was sufficient to increase hamstring flexibility and a lack of stretching can cause reduction of muscle performance.
\end{abstract}

Key words: Homes for the aged; Muscle stretching exercises; Muscle strength; Flexibility; Activities of daily living

\section{Introduction}

The Brazilian Institute of Geography and Statistics (1) has estimated that $8.6 \%$ of the Brazilian population (14.4 million) are composed of elderly citizens. According to the Institute, the growth experienced during the last 10 years was of $17 \%$ and projections indicate that this population may reach 55.0 million people ( $27 \%$ of the total population) by the year 2040. As the aging population increases so also will the number of people living in nursing homes (2). The institutionalized elderly have a different profile than noninstitutionalized persons (3). For instance, physical disability, functional loss and autonomy, psychosocial context, stress, family support, and loss of an identity role in the community cause difficulties in basic daily activities and cognitive skills and increase the risk of falling (2-4).

It has been shown that independence is closely related to the ability to sustain the functional status of the neuromuscular system (5). Furthermore, exercise programs have shown a reduction in the rate of falling and improved balance and mobility $(4,6)$.

In general, most physical activity and exercise programs are designed to improve the force-generating characteristics of skeletal muscles, specifically by increasing strength or

Correspondence: D. Gallon, Av. Presidente Kennedy, 1823, Apto. 13, 80610-010 Curitiba, PR, Brasil. E-mail: danigallon@hotmail.com

This trial is registered and allocated the ACTRN: ACTRN12610001105033.

Received August 9, 2010. Accepted January 17, 2011. Available online January 28, 2011. Published March 7, 2011. 
power in the active elderly (7). In fact, increasing muscle strengthening has been confirmed to be one of the most effective ways to reduce the debilitating effects of ageing on functional performance (4). However, a major part of the current literature has only reported the effect of multicomponent exercise interventions and lacks studies assessing the effects of stretching alone $(4,8)$.

For example, some outcomes have shown that the elderly benefit from a stretching program in which the gains in range of motion were translated into better performance over a number of gait-related variables $(9,10)$.

Therefore, muscle-tendon alterations associated with the ageing process especially affect the bi-articular muscles, such as knee flexors and extensors, limit the range of motion, and change torque distribution around joints (11-15). Thus, stretching exercises can be an important tool in minimizing these losses.

To the best of our knowledge, no more than one study has reported strength gains after a stretching program using proprioceptive neuromuscular facilitation in the institutionalized aged (16). Other investigators have also found an increase in torque after a stretching program in a standing position, but performed by non-institutionalized older women $(17,18)$.

Consequently, musculoskeletal adaptation induced by active stretching exercises in the institutionalized elderly, who experience difficulties in engaging in more strenuous training programs, needs to be further explored. In addition, the studies that analyzed the effects of stretching programs designed to improve flexibility did not fully assess muscle strength changes $(14,19)$. Thus, there is limited information about the effects of stretching on the torque-producing ability of institutionalized older women. Assessment of muscle strength provides information about the extent of muscle weakness caused by ageing conditions. Hence, muscle strength is a component of human performance and is an important measure for the characterization of the functional capability of an individual (15).

For these reasons, the objective of the present study was to investigate the effects of an active static stretching program ( 3 sessions per week for 8 weeks) on the hamstring muscle in a group of institutionalized older women. Peak eccentric and concentric torques of agonist and antagonist knee muscle groups, muscle-tendon length of uni- and biarticular hip flexors, hamstring flexibility, and activities of daily living were used to investigate the influence of the stretching program on female nursing home residents.

\section{Material and Methods}

\section{Subjects}

Initially, 142 women were contacted via the administration of a long-term care facility. Sixty-one women were excluded from the study as they were limited in their mobility (use of a wheel chair, cane or other walking device),
10 were found to experience health problems and 52 had physical restrictions in performing physical activities. Thus, 19 women $(67.0 \pm 9.0$ years old; $72.4 \pm 17.1 \mathrm{~kg}$, and $1.54 \pm$ $0.08 \mathrm{~m}$ ) volunteered and were eligible to participate in the study. Age, weight and height were similar for all subjects $(P>0.05)$. All participants had been living in the facility care unit for at least $22.0 \pm 16.0$ years and were medically stable. The recruitment and selection criteria are described in Figure 1. All procedures used in the present study were approved by the Ethics Committee of the Federal University of Paraná (CAAE-0003.0.91.000-09) and written informed consent was obtained from all participants after a detailed explanation of the procedures and requirements of the experiments.

After recruitment, subjects were randomly assigned to either the control group ( $C G ; N=9$ ), which received educational talks about healthy habits and cultural activities, or to the group enrolled in a stretching program (SG; $\mathrm{N}=10$ ) (20). Both groups (CG and $S G$ ) attended sessions three times per week for 8 weeks, for a total of 24 sessions. Unfortunately, 2 participants were excluded from the SG due to cellulitis in the lower limbs.

A brief warm-up of 10 min of ludic activities and walking was carried out before the stretching exercises (21). Then, the stretching exercises for hamstring muscles were performed in a sitting position with an extended knee with a thick non-elastic band (1 $\mathrm{m}$ in length) placed around the foot of the stretched limb to allow subjects to pull themselves forward with both hands. The lower segment was gradually extended with the trunk leaning forward to a position in which participants felt discomfort for a period of $60 \mathrm{~s}$. The corresponding limb maintained knee and hip joint flexed and with the foot flat on the floor. Four consecutive repetitions of $60 \mathrm{~s}$ each were performed and an interval of $60 \mathrm{~s}$ was allowed before exercising the opposite $\operatorname{limb}(19,22,23)$.

Before starting the interventions, all participants underwent two assessment sessions. The first assessment session was used to familiarize the elderly women with the peak torque measurements in the isokinetic dynamometer (Cybex NORM, division of Lumex, Inc., USA). In addition, participants underwent the following evaluations: MiniMental State Examination (MMSE), Barthel Index and Lysholm Scoring Scale. The MMSE questionnaire was applied to determine the cognitive ability of the subjects according to educational level, and the score had to be more than 13 (24). The Barthel Index was applied to establish the activities of daily life and the score also had to be more than 13 (25). The Lysholm Scoring Scale was applied to assess knee functional status and the presence or absence of signs of instability. Thus, to be included in this trial, the subject had to receive a minimum score of 84 , i.e., knee function fair to good (26).

The flexibility, muscle-tendon length, isokinetic eccentric and concentric peak torques of the knee flexor and extensor muscles were determined in the second assessment 
session. Specific procedures are reported below in detail. The same tests (stretching training/ludic activities) were applied after the intervention period (i.e., 8 weeks later) and followed the same sequence.

\section{Assessment of muscle-tendon length and flexibility}

The muscle-tendon length and flexibility were determined by the Photogrammetric Method using a digital camera (Canon, model Power A95, Japan) positioned perpendicularly at $\sim 2.7 \mathrm{~m}$ to the sagittal plane of the subjects. The focus of the camera aimed at the center of the relevant joints and the following landmarks were identified: greater trochanter (GT), lateral epicondyle (LE) of the femur, and malleolus of the fibula (MA). These points defined the thigh (GT-LE) and shank (LE-MA) segments. The angle between these segments was determined using the angular dimension tool, which is available in commercial image processing software (Corel Drawl, version 13) and followed the recommendations proposed by Sarraf et al. (27). Initially, the modified "Thomas" test was applied (27). The test is used to determine muscle-tendon length of the hip uni- and biarticular flexor muscles. A comprehensive description of the test can be obtained elsewhere (27). Briefly, the participant was positioned in the supine posture with the knee joint of the tested segment flexed, with the thigh supported on the table and the shank hanging down from the edge of the table. The experimenter actively flexed the opposite segment until the hip reached $125^{\circ}$ of flexion, while the tested segment hung free. Thus, the angle between the initial and final positions of the thigh with respect to the horizontal line

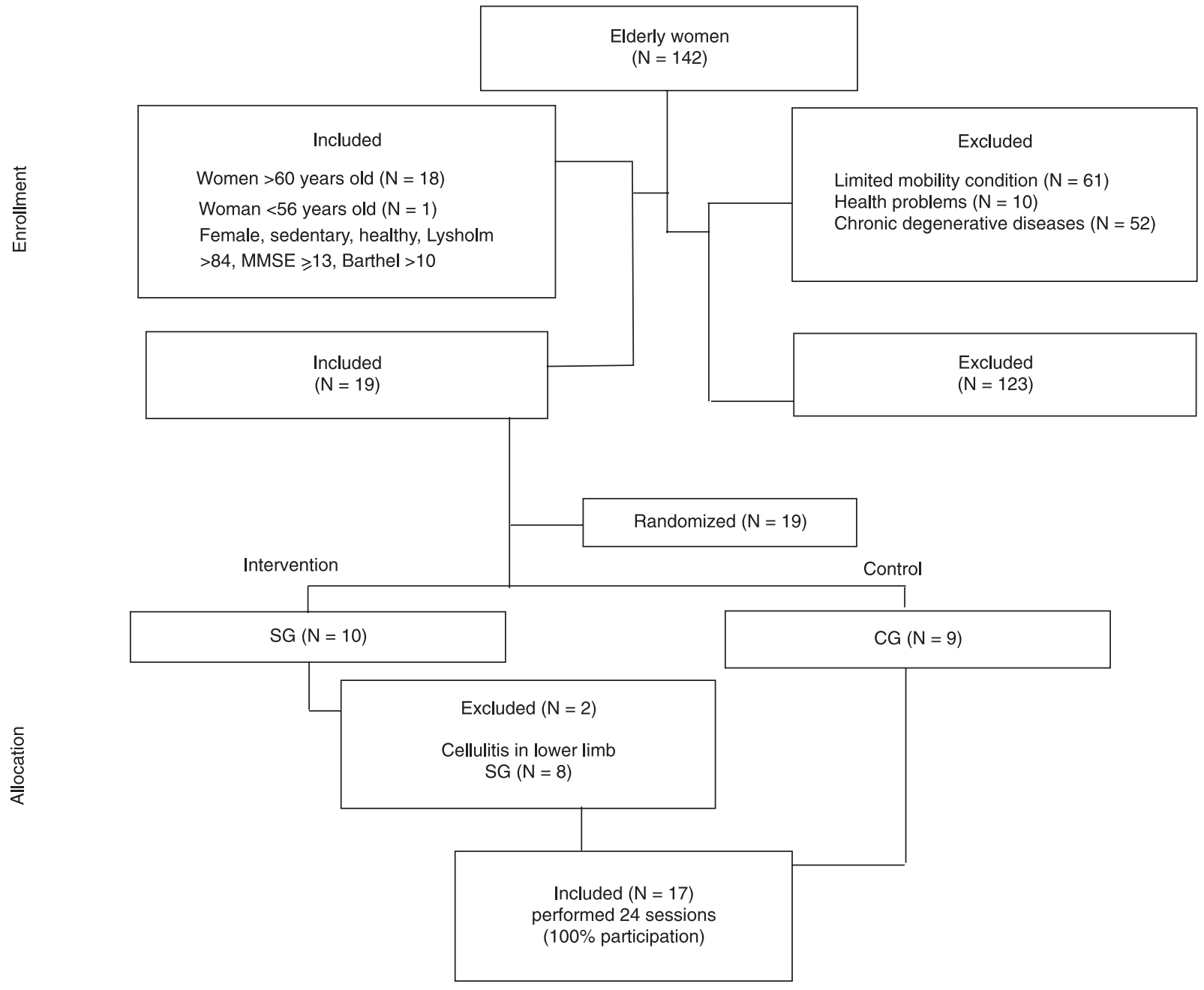

Figure 1. Study design. Flow of participants through the study. Nineteen institutionalized female elderly nursing home residents were randomized to the stretching group ( $S G, N=10)$ or to the control group $(C G, N=9)$. A total of 17 participants completed the study. MMSE = Mini-Mental State Examination. 
(Table 1) and at the knee joint was measured.

After the Thomas test, the flexibility of the hamstrings was assessed by the passive straight-leg-raising test $(28,29)$. The tested segment was slowly lifted by the experimenter until some discomfort was felt in the popliteal region and the other segment was stabilized in an extended position using adjustable straps. The initial and final positions were photographed and the angle between the elevated thigh and the horizontal line (Table 1) was quantified. Values above $65^{\circ}$ were deemed as normal, and lower values were considered to indicate decreased flexibility.

\section{Torque assessment}

Peak torque was measured using an isokinetic dynamometer (Cybex NORM, division of Lumex, Inc.). Assessments were performed according to the guidelines of the manufacturer and the procedures are described elsewhere (30). Gravity correction was calculated using the procedures established in the software equipment (Cybex Software, version 2.06). Each participant sat secured by adjustable straps and was requested to fold her arms in front of the chest region. Participants received verbal encouragement and visual feedback was provided by the PC monitor in an attempt to obtain maximal performances.

The eccentric and concentric actions of the knee flexor and extensor muscles were tested at $60 \%$ s. Initially, a set of three submaximal attempts was allowed prior to the proper test to permit the participants to familiarize themselves with the demands and requirements of the assessment. Then, tests were repeated three times with an interval of 2 min between trials. The order of the tests was randomly assigned. Blood pressure (Premium - G-Tech sphygmomanometer, China) was monitored throughout the test.

\section{Statistical analysis}

Standard descriptive statistics were calculated for all variables. The normality of the data was determined using the Shapiro-Wilk test and homogeneity was assessed by the Levene test. When the results were homogeneous and normally distributed, two-way analysis of variance for independent samples was applied. The Fisher test was applied to determine where differences occurred. Wilcoxon and MannWhitney tests were used where normality or homogeneity was not found. The level of significance was set at $5 \%$ for all comparisons and all analyses were performed using a specific software (Statistica, version 7.0 ${ }^{\circledR}$, USA).

\section{Results}

The 8-week stretching training program improved hamstring flexibility with respect to the initial condition $(P<$ 0.05). The SG experienced a hamstring flexibility increase of $30 \%$ compared to the values found before intervention (76.5 $\pm 13.0^{\circ}$ vs $\left.59.5 \pm 9.0^{\circ}, \mathrm{P}=0.0002\right)$. In addition, the SG also showed greater increases in the flexibility of knee flexor muscles when compared to the CG $\left(76.5 \pm 13.0^{\circ} \mathrm{vs}\right.$ $64.0 \pm 12.0^{\circ}, \mathrm{P}=0.0018$ ).

The ability to stretch the hip biarticular flexors of the CG was reduced when compared to initial values (124.0 \pm $6.8^{\circ}$ vs $\left.118.3 \pm 7.6^{\circ} ; P=0.031\right)$. Table 1 demonstrates the data for flexibility and muscle-tendon length changes that occurred in response to the stretching program.

No peak torque differences in knee extensor or flexor muscle groups were found in the $S G(P>0.05)$, irrespective of the contraction type (eccentric or concentric). However, the knee extensor eccentric peak torques of the CG decreased $(15.7 \%)$ after the experimental period (post $=-49.4$ \pm 16.8 vs pre $=-60.5 \pm 18.9 \mathrm{Nm}, \mathrm{P}=0.048$; Fisher test) .

The Lysholm Knee Score, Barthel Index and MMSE showed no differences between groups $(P>0.05)$. In addition, results were stable across the intervention period $(P>0.05)$.

Table 1. Photogrammetry of hamstring flexibility and muscle-tendon lengths of the uni- and biarticular hip flexors of institutionalized older women.

\begin{tabular}{lcccc}
\hline Test & Group & $\begin{array}{c}\text { Pre-intervention } \\
\text { dominant leg }\left({ }^{\circ}\right)\end{array}$ & $\begin{array}{c}\text { Post-intervention } \\
\text { dominant leg }\left({ }^{\circ}\right)\end{array}$ & Relative difference (\%) \\
\hline Hamstring flexibility & CG & $58.6 \pm 7.0$ & $64.0 \pm 12.0^{*}$ & $9.2 \pm 14.3$ \\
& SG & $59.5 \pm 9.0$ & $76.5 \pm 13.0^{+}$ & $30.0 \pm 18.0$ \\
Hip uniarticular flexors & CG & $18.1 \pm 3.0$ & $18.4 \pm 4.0$ & $-1.7 \pm 22.7$ \\
& SG & $15.5 \pm 3.5$ & $20.1 \pm 8.5$ & $31.4 \pm 74.0$ \\
Hip biarticulars flexors & CG & $118.3 \pm 7.6$ & $124.0 \pm 6.8^{\#}$ & $5.0 \pm 7.0$ \\
& SG & $118.6 \pm 9.4$ & $121.1 \pm 10.9$ & $2.3 \pm 7.6$ \\
\hline
\end{tabular}

Data are reported as means $\pm S D$. CG = control group; SG = stretching group. Relative difference was calculated through the following equation: pre-intervention values - post-intervention values / pre-intervention values $\times 100$. ${ }^{*} P=0.0018$ compared to $S G$ post-intervention. ${ }^{+} P=$ 0.0002 compared to pre-intervention. ${ }^{\#} \mathrm{P}=0.031$ compared to pre-intervention (Wilcoxon and Mann-Whitney tests). 


\section{Discussion}

The active stretching protocol performed only three times per week induced an increase in hamstring flexibility in nursing home women residents. Therefore, the main findings of the present study were: i) decreased flexibility in all institutionalized older women studied before the experimental period; ii) increased flexibility of knee flexors after the stretching exercise program; iii) declined muscletendon length and eccentric torque of knee extensor of the non-trained group.

All participants from both groups showed below normal flexibility values $\left(<65^{\circ}\right)$ before the study (29) that could be attributed to a decrease in the magnitude of maximal passive resistive force, which indicates a marked decrease in the maximal length associated with the aging process (12). These muscle-tendon changes can be caused by an increase in type I collagen and/or a decrease in type III collagen $(12,31)$.

However, it was interesting to observe in the present study that active static stretching training, performed only three times per week, was sufficient to induce an increase in hamstring flexibility above normal values in institutionalized older females. This result was better than that obtained by other investigators who submitted aged people to a daily passive stretching program for 6 weeks (19). The increase observed in the present study can be attributed to the active characteristics of the stretching technique, the longer duration of the training program, i.e., 8 weeks, and also the profile of the participants. It has been documented that active protocols are more effective in providing a greater gain than passive exercises (31).

Other factors may have contributed to the changes observed in the present study, such as Golgi tendon organs and muscle spindle adaptation (32), which may have allowed increased tolerance to stretching (33) and a possible addition of sarcomeres in series (34).

Moreover, the group that performed stretching exercises (SG) did not show as marked a reduction of flexibility of the knee extensor muscles during the course of the experiment as CG. This outcome could be explained by an increase in antagonist coactivation, which could have reduced the elastic rigidity of the passive viscoelastic elements of the muscle-tendon unit $(12,31,35)$.

The elderly women who did not exercise showed a further flexibility decline during the period of the experiment and once again demonstrated the negative effects of the lack of physical activity, which is generally found in the institutionalized elderly $(4,36,37)$. Although the loss of flexibility and muscle strength deficit are common among institutionalized elderly subjects, the stretching training performed in the present study was sufficient to prevent reduction of flexibility even in the antagonist muscles (4).

Peak flexor or extensor torques remained unchanged after the stretching training despite the changes observed in hamstring flexibility. These results agree with other studies in which peak torque did not respond to a program of stretching exercises $(8,38)$. On the other hand, the group that did not exercise experienced a decline in the eccentric peak torque of the knee extensor muscles, which can be related to the reduction of muscle-tendon length in the hip bi-articular flexor muscles. In addition, the increasing loss of muscle strength beginning from the 4th decade is more pronounced after the 6 th decade and is further accelerated by the lack of physical activity induced by institutionalization $(31,36,37)$.

Although the stretching program did not cause an increase in peak torque, nonetheless it was successful in preventing a further loss of muscle function, which can contribute to mobility. Consequently, this outcome is very relevant because strength of lower extremity muscles is an important determinant of mobility-based functional activities as rising from a chair or stair negotiation (15). The unchanged peak torque found in the present study may be attributed to institutionalization and/or the stretching technique performed $(17,18,37)$.

To the best of our knowledge, this is the first report that has investigated the effect of stretching on isokinetic peak torque in older women living in a nursing home. Therefore, when the peak torque of non-institutionalized elderly of other studies is compared to the results of the present study, a clear difference is noticed $(17,18,39)$. It is interesting to observe that the peak torques of the institutionalized elderly women found in the present study were lower than those of active elderly subjects aged 70 to 80 years (39).

All elderly women analyzed were independent in their daily life tasks. The Barthel index remained unchanged after 8 weeks. The subjects showed good knee functionality (Lysholm Scoring Scale), and the training program did not interfere with the cognitive aspects (MMSE).

The present study has some limitations, specifically the reduced size of the sample per group (SG, N = 8 and CG, $\mathrm{N}=9$ ), which may have influenced the impact of the investigation. Using the equation of Luiz and Magnanini (40) to calculate the sampling size, we found that 16 subjects per group would be the number needed to test the hypothesis of the present study. However, on the basis of the eligibility criteria, it was not possible to include this number in each group, especially because of the profile of institutionalized elderly women to be enrolled in the stretching program. Hence, future studies should include more than one nursing home to obtain a suitable sample size.

Additionally, other studies should include passive torque and analysis of the length-tension muscle-tendon properties, which may provide a better understanding of the effects of stretching training on muscle adaptation in institutionalized older subjects. Nevertheless, we should emphasize the important contribution of active stretching exercises, performed three times per week, to increase flexibility and to prevent loss of muscle performance in female nursing home residents. 
We believe that an active stretching program should be added to the routine of institutionalized elderly subjects because it has been shown here to be effective not only in increasing knee flexor flexibility but also in preventing loss of knee extensor performance.

\section{Acknowledgments}

We gratefully acknowledge the help and support of the staff and residents of the São Vicente de Paulo assistedliving in Curitiba, PR, and the Knee Clinic for providing their facilities to perform the isokinetic assessments. In addition, we wish to thank Jack Lagan, Italian Wilkins Public School, Park St. Marrickville, NSW Sydney, Australia, for revising the English text of the paper. Research supported by Universidade Federal do Paraná, Clínica do Atleta, Asilo São Vicente de Paulo de Curitiba. A.L.F. Rodacki and A.R.S. Gomes are recipients of productivity fellowships from CNPq.

\section{References}

1. IBGE. Estimativas de projeção da população. IBGE; 2008.

2. Andresen M, Runge U, Hoff M, Puggaard L. Perceived autonomy and activity choices among physically disabled older people in nursing home settings: a randomized trial. J Aging Health 2009; 21: 1133-1158.

3. Coelho FM, Narciso FM, Oliveira DM, Pereira DS, Teixeira $\mathrm{AL}$, Teixeira MM, et al. sTNFR-1 is an early inflammatory marker in community versus institutionalized elderly women. Inflamm Res 2010; 59: 129-134.

4. Weening-Dijksterhuis E, de Greef MH, Scherder EJ, Slaets JP, van der Schans CP. Frail institutionalized older persons: a comprehensive review on physical exercise, physical fitness, activities of daily living, and quality-of-life. Am J Phys Med Rehabil 2010

5. Runge M, Rehfeld G, Resnicek E. Balance training and exercise in geriatric patients. $J$ Musculoskelet Neuronal Interact 2000; 1: 61-65.

6. Lord SR, Castell S, Corcoran J, Dayhew J, Matters B, Shan $A$, et al. The effect of group exercise on physical functioning and falls in frail older people living in retirement villages: a randomized, controlled trial. J Am Geriatr Soc 2003; 51: 1685-1692.

7. Strasser B, Keinrad M, Haber P, Schobersberger W. Efficacy of systematic endurance and resistance training on muscle strength and endurance performance in elderly adults - a randomized controlled trial. Wien Klin Wochenschr 2009; 121: 757-764.

8. Bird ML, Hill K, Ball M, Williams AD. Effects of resistanceand flexibility-exercise interventions on balance and related measures in older adults. J Aging Phys Act 2009; 17: 444454.

9. Kerrigan DC, Lee LW, Collins JJ, Riley PO, Lipsitz LA. Reduced hip extension during walking: healthy elderly and fallers versus young adults. Arch Phys Med Rehabil 2001; 82: $26-30$.

10. Cristopoliski F, Sarraf TA, Dezan VH, Provensi CLG, Rodacki ALF. Transient effect of flexibility exercises in the hip joint on the gait of older women. Efeito transiente de exercícios de flexibilidade na articulação do quadril sobre a marcha de idosas. Rev Bras de Med do Esporte. Rev Bras Med Esporte 2008; 14: 139-144.

11. Safran C, Slack WV, Bleich HL. Role of computing in patient care in two hospitals. MD Comput 1989; 6: 141-148.

12. Gajdosik RL, Vander Linden DW, McNair PJ, Riggin TJ, Albertson JS, Mattick DJ, et al. Slow passive stretch and release characteristics of the calf muscles of older women with limited dorsiflexion range of motion. Clin Biomech 2004;
19: 398-406.

13. Gajdosik RL, Vander Linden DW, McNair PJ, Riggin TJ, Albertson JS, Mattick DJ, et al. Viscoelastic properties of short calf muscle-tendon units of older women: effects of slow and fast passive dorsiflexion stretches in vivo. Eur J Appl Physiol 2005; 95: 131-139.

14. Gajdosik RL, Vander Linden DW, McNair PJ, Williams AK, Riggin TJ. Effects of an eight-week stretching program on the passive-elastic properties and function of the calf muscles of older women. Clin Biomech 2005; 20: 973-983.

15. Samuel $D$, Rowe PJ. Effect of ageing on isometric strength through joint range at knee and hip joints in three age groups of older adults. Gerontology 2009; 55: 621-629.

16. Klein DA, Stone WJ, Phillips WT, Gangi J, Hartman S. PNF training and physical function in assisted-living older adults. J Aging Phys Act 2002; 10: 476-488.

17. Batista LH, Camargo PR, Oishi J, Salvini TF. Effects of an active eccentric stretching program for the knee flexor muscles on range of motion and torque. Rev Bras Fisioter 2008; 12: 176-182.

18. Batista LH, Vilar AC, de Almeida Ferreira JJ, Rebelatto JR, Salvini TF. Active stretching improves flexibility, joint torque, and functional mobility in older women. Am J Phys Med Rehabil 2009; 88: 815-822.

19. Feland JB, Myrer JW, Schulthies SS, Fellingham GW, Measom GW. The effect of duration of stretching of the hamstring muscle group for increasing range of motion in people aged 65 years or older. Phys Ther 2001; 81: 1110-1117.

20. Thomas J, Nelson J, Silverman S. Research methods in physical activity. Champaign: Human Kinetics; 2005.

21. Agre JC, Pierce LE, Raab DM, McAdams M, Smith EL. Light resistance and stretching exercise in elderly women: effect upon strength. Arch Phys Med Rehabil 1988; 69: 273-276.

22. Taylor DC, Dalton JD Jr, Seaber AV, Garrett WE Jr. Viscoelastic properties of muscle-tendon units. The biomechanical effects of stretching. Am J Sports Med 1990; 18: 300-309.

23. Chan SP, Hong Y, Robinson PD. Flexibility and passive resistance of the hamstrings of young adults using two different static stretching protocols. Scand J Med Sci Sports 2001; 11: 81-86.

24. Bertolucci PH, Brucki SM, Campacci SR, Juliano Y. [The Mini-Mental State Examination in a general population: impact of educational status]. Arq Neuropsiquiatr 1994; 52: 1-7.

25. Wade DT, Collin C. The Barthel ADL Index: a standard measure of physical disability? Int Disabil Stud 1988; 10: 
64-67.

26. Peccin MS, Ciconelli R, Cohen M. Questionário específico para sintomas do joelho "Lysholm Knee Scoring Scale" tradução e validação para a língua portuguesa. Acta Ortop Bras 2006; 14: 268-272.

27. Sarraf T, Dezan VH, Rodacki ALF. Diferenças entre medidas qualitativas e quantitativas durante testes de comprimento músculo-tendíneos dos flexores do quadril uni e bi-articulares. Rev Bras Fisioter 2005; 9: 195-202.

28. Bohannon RW. Cinematographic analysis of the passive straight-leg-raising test for hamstring muscle length. Phys Ther 1982; 62: 1269-1274.

29. Carregaro RL, Silva LCCB, Coury HJC. Comparison between two clinical tests for evaluating the flexibility of the posterior muscles of the thigh. Rev Bras Fisioter 2007; 11: 139-145.

30. Wu G, Siegler S, Allard P, Kirtley C, Leardini A, Rosenbaum $D$, et al. ISB recommendation on definitions of joint coordinate system of various joints for the reporting of human joint motion - part I: ankle, hip, and spine. International Society of Biomechanics. J Biomech 2002; 35: 543-548.

31. Ferber R, Osternig L, Gravelle D. Effect of PNF stretch techniques on knee flexor muscle EMG activity in older adults. $J$ Electromyogr Kinesiol 2002; 12: 391-397.

32. Nelson RT, Bandy WD. Eccentric training and static stretching improve hamstring flexibility of high school males. J Athl
Train 2004; 39: 254-258.

33. LaRoche DP, Connolly DA. Effects of stretching on passive muscle tension and response to eccentric exercise. Am J Sports Med 2006; 34: 1000-1007.

34. Gajdosik RL. Passive extensibility of skeletal muscle: review of the literature with clinical implications. Clin Biomech 2001; 16: 87-101.

35. Folland JP, Williams AG. The adaptations to strength training: morphological and neurological contributions to increased strength. Sports Med 2007; 37: 145-168.

36. McMurdo ME, Rennie LM. Improvements in quadriceps strength with regular seated exercise in the institutionalized elderly. Arch Phys Med Rehabil 1994; 75: 600-603.

37. Bastone AC, Jacob Filho W. Effect of an exercise program on functional performance of institutionalized elderly. $J$ Rehabil Res Dev 2004; 41: 659-668.

38. LaRoche DP, Lussier MV, Roy SJ. Chronic stretching and voluntary muscle force. J Strength Cond Res 2008; 22: 589596.

39. Frontera WR, Reid KF, Phillips EM, Krivickas LS, Hughes $V A$, Roubenoff $R$, et al. Muscle fiber size and function in elderly humans: a longitudinal study. J Appl Physiol 2008; 105: 637-642.

40. Luiz RR, Magnanini MMF. A lógica da determinação do tamanho da amostra em investigações epidemiológicas. Cad Saúde Coletiva 2000; 8: 9-28. 